\title{
o Processo de Trabalho do Militar Estadual e a Saúde Mental'
}

\section{Working Process of Military Police State Officers and Mental Health'}

\author{
Maurivan Batista da Silva \\ Mestre em Engenharia de Produção, na área de Tecnologia, Tra- \\ balho e Organizações. \\ Endereço: Rua Francisco Jorge, 03, Centro, CEP 58306-ı80, Bayeux, \\ $P B$, Brasil. \\ E-mail: maurivanbatista®yahoo.com.br \\ Sarita Brazão Vieira \\ Professora Doutora do Departamento de Psicologia da Universi- \\ dade Federal da Paraíba - UFPB. Colaboradora do Programa de \\ Pós-Graduação em Engenharia de Produção e Psicologia Social \\ da UFPB. \\ Endereço: Rua Mar Báltico 126 apt.104, CEP 58310-000, Intermares, \\ Cabedelo PB, Brasil. \\ E-mail: saritaœterra.com.br \\ 1 Este texto apresenta resultados parciais da dissertação de \\ mestrado do primeiro autor, defendida em 2007 no Programa \\ de Pós-Graduação em Engenharia de Produção (PPGEP/UFPB), na \\ área de Tecnologia, Trabalho e Organizações, intitulada "Traba- \\ Iho da Polícia Militar e Saúde Mental: um estudo de caso sobre o \\ sofrimento psíquico e prazer na atividade de radiopatrulha", sob \\ a orientação da Profa Dr. Sarita Brazão Vieira.
}

\section{Resumo}

A Polícia Militar está balizada em dois pilares fundamentais: a disciplina e a hierarquia. O que a faz uma organização complexa com feixes de interesses que obstam a capacidade de resistência à mudança. Identificar como essa organização se estrutura e, sobretudo, relacioná-la com a saúde mental é o objetivo deste artigo. Buscamos contextualizar as finalidades dos serviços de segurança pública via breve histórico da polícia estadual, sua divisão e aplicabilidade frente à violência cotidiana. Através da psicologia do trabalho, usamos técnicas e conceitos fundamentados na Ergonomia da Atividade e na Psicodinâmica do Trabalho: observação do processo de trabalho, pesquisa documental, entrevistas individuais e coletivas. A análise de natureza qualitativa demonstrou que o policial militar está no centro de uma conjugação de forças advindas da organização do trabalho, da precarização do trabalho e, por fim, da sociedade contemporânea. As formas como essas relações de forças se conjugam, contribuem para implicações danosas à saúde (mental) dos profissionais, cuja configuração favorece o aumento do sofrimento psíquico, podendo se desdobrar em alcoolismo, depressão e até em suicídio. Dados da Junta Médica, de 2003 a 2005, mostram uma média de 489 policiais militares afastados do serviço por licenças médicas. Trata-se de números preocupantes em uma área de serviço público essencial à população. Esses números seriam maiores se as liberações ocorridas no local de trabalho também fossem computadas. 0 procedimento de liberação interna ocorre para tentar mediar os possíveis longos períodos na atividade para tratamento de saúde.

Palavras-chave: Polícia militar; Organização do trabalho; Saúde mental. 


\section{Abstract}

The Military Police are guided by two fundamental pillars: discipline and hierarchy making them a complex organization with groups of interests that hinder their capacity to change. The aim of the present study is to identify how the organization is structured and to relate it to mental health. We tried to contextualize the purposes of public safety services through a brief history of the state police, its division and how it has been used against daily violence. Based on labor psychology view, we made use of techniques and concepts based on the Ergonomics of the Activity and on Labor Psychodynamics; observing the work process, document research, individual and collective interviews. Qualitative analysis demonstrated that military officers are in the center of a link of forces coming from work organization, the precariousness of the work and, finally, from the contemporary society. The ways these relationships of forces are joined contribute to harmful implications to the mental health of professionals, favoring the increase in psychological suffering and it can lead to alcoholism, depression, and even suicide. Data from Medical Council of João Pessoa, (2003 to 2005), show an average of 489 military officers who retired from work on medical grounds. These are worrisome figures in an area of public service that is essential to the population. These figures would be higher if the leaves granted in the workplace were also included. Procedures for granting internal leaves occur in an attempt to mediate the possible long period of health treatment.

Keywords: Work Organization; Military Police; Mental Health.

\section{Introdução}

Enquanto instituição, a Polícia Militar (PM) do Brasil tem uma estrutura burocrática, com raízes no século XIX, cuja lógica sofreu reconfigurações no período dos governos militares. Mesmo com essas mudanças, o princípio de atuação se manteve, com o impedimento de qualquer ideia de contestação social de grupos legais (ou ilegais) contrários ao poder vigente na época.

Mas a atual conjuntura social, pela qual passa a sociedade brasileira, diferencia-se daquela de tempos idos. Hoje, a PM não tem como prioridade acompanhar ou coibir esses grupos, uma vez que existe uma realidade cadenciada pelo aumento da violência difusa na sociedade e da criminalidade. Além disso, as sociedades contemporâneas se caracterizam por um descompasso crescente em relação às políticas públicas de cunho social e de infraestrutura.

Ao se deparar com essa situação, os estudiosos da área de segurança pública chegam a questionar a eficiência da organização do trabalho que a PM brasileira emprega. Nesse contexto, a percepção de insegurança pública torna-se visível e preocupante, para não dizer assustadora, nas grandes cidades.

Ao discutir os dados fornecidos pelo Sistema de Informação sobre Mortalidade do Ministério de Saúde (SIM/MS), no período entre 1979 e 2003, Peres (2006) afirma que em 1979 foram registrados 11.194 óbitos por homicídio. Em 2003, esse número disparou para 51.043 , com um aumento equivalente a $356 \%$ entre um registro e outro. O número absoluto de 758.293 pessoas assassinadas, a maioria entre 15 e 39 anos, demonstra o crescimento bem expressivo de homicídios no Brasil.

Segundo Silva Filho (2003), somente na década de 1990, os homicídios cresceram $29 \%$, sendo que entre os jovens esses dados aumentaram para $48 \%$. Com $3 \%$ da população mundial, o Brasil concentra $9 \%$ dos homicídios cometidos no planeta. Outros elementos também compõem essa atmosfera de insegurança, tais como roubos, furtos, sequestros longos e sequestrosrelâmpago.

Na cidade de João Pessoa-PB, os números não são em nada tranquilizantes. Segundo a Secretaria Nacional de Segurança Pública, entre 2001 e 2003 a polícia civil dessa cidade registrou um aumento de $28,2 \%$ nas ocorrências, dados acima da média nacional (de 6.o85,8 ocorrências) (SENASP, 20o6). 0 número de crimes envolvendo drogas e as tentativas de homicídios 
fizeram de João Pessoa a primeira capital com maior crescimento em taxa de delitos relacionados a drogas, com aumento de $451,1 \%$, e a segunda com aumento na taxa de homicídios, com 205,6\%. Essas percentagens causam preocupação, apesar de os números da criminalidade e da violência terem mostrado certo declínio nos anos de 2004 e 2005.

Segundo Fernandes (2007), a SENASP encontra certa dificuldade na tabulação desses dados. Isso ocorre porque a secretaria reconhece uma qualidade questionável nos registros das informações que as polícias e o Sistema de Informação sobre Mortalidade (SIM), do Ministério da Saúde, fornecem. Esses dados chegam a ser conflitantes entre si.

Ao se depararem com esse fenômeno social, cotidiano e crítico, os militares estaduais, principalmente os que desempenham uma atividade-fim, atuam com os instrumentos que lhes são próprios. Todavia, a atuação nessa linha de frente - com o propósito inibitório da violência - expõe os PMs, especificamente os de policiamento ostensivo, a um conjunto de exigências, advindas tanto da organização do trabalho policial quanto das características da sociedade contemporânea (Gouveia, 1999).

Por isso, a intenção deste estudo é investigar os dados sobre as relações entre a organização do trabalho da PM e a saúde mental de seus profissionais, quando no exercício de sua atividade-fim (policiamento ostensivo), na cidade de João Pessoa-PB. Partimos do pressuposto de que a sinergia dessas forças (organização do trabalho, precarização do trabalho e sociedade marcada pela insegurança) pode trazer danos sistemáticos para a saúde mental dos PMs.

Para tanto, o presente trabalho contextualiza as finalidades dos serviços de segurança pública, mostrando alguns aspectos relativos ao nascimento da Polícia Militar (PM) no Brasil e como a polícia estadual se coloca na estruturação geral. Em seguida, levantamse algumas questões sobre a aplicabilidade do modelo de organização do trabalho da PM frente às demandas da sociedade atual, marcada pela crescente violência social e as repercussões desse modelo na saúde dos policiais militares.

\section{Aspectos Metodológicos}

No presente estudo, de caráter qualitativo do tipo exploratório-descritivo, foram utilizados 19 policiais militares da cidade de João Pessoa, na Paraíba, sendo sete deles considerados de maneira individual, enquanto 12 eram integrantes dos grupos de discussão utilizados, distribuídos em quatro grupos. Como instrumentos para a coleta dos dados, foram empregadas técnicas fundamentadas na Ergonomia da Atividade e na Psicodinâmica do Trabalho, tais como a observação do processo de trabalho e a pesquisa documental, além de entrevistas individuais e coletivas.

Cada grupo de discussão era composto por três policiais militares (PMs) da radiopatrulha e as discussões duravam aproximadamente uma hora. A questão inicial, que serviu como elemento desencadeante das discussões, compreendeu o seguinte tema: "Lideranças militares vêm se preocupando com o crescimento do alcoolismo, da depressão e do suicídio na Polícia Militar (PM). O que vocês pensam sobre isso? $\varepsilon$ o que favorece a instalação desse quadro preocupante?". As entrevistas seguiram um roteiro prévio, contendo os seguintes grupos temáticos: dados profissionais, dados da saúde, estrutura temporal do trabalho, aspectos da hierarquia, padrão de comunicação, divisão e conteúdo das tarefas e política de pessoal ${ }^{2}$.

O critério principal que determinou a composição dos participantes da pesquisa foi o de que cada policial desempenhasse sua função na modalidade de radiopatrulha (RP) e que a sua participação fosse voluntária. A composição de cada grupo era de PMs de patentes distintas, que constituíam uma guarnição - soldado, cabo e/ou sargento. As sessões foram gravadas em áudio, após a permissão dos participantes.

Além da entrevista, que possibilitou o acesso ao discurso subjetivo do trabalho prescrito e do trabalho real (Dejours, 1987), empregamos a técnica de observação livre. Segundo Guérin e colaboradores (2004), pode-se afirmar que a observação em si é o processo que permite ter conhecimento dos aspectos que compõem uma dada situação. As observações permitiram acompanhar a mobilização da categoria por melhores condições

\footnotetext{
2 As entrevistas individuais iniciaram em março de 2006, época em que os PMs se alojaram em praça pública para reivindicar melhorias no trabalho. O termo que a categoria empregou para melhor designar tal mobilização foi o de "vigília”, já que é vedado ao militar fazer greve. Isso demonstra a capacidade dos trabalhadores de reinventar (reinterpretar) normas e leis para reivindicar melhoramento das condições de trabalho e de salários.
} 
de trabalho. Tanto a "vigília" quanto as passeatas dos PMs pelas principais ruas da capital (João Pessoa) permitiram acessar questões sobre o porquê e o como da relação vivência-trabalho. Essa situação, visível na fala da categoria sobre a precarização do trabalho, mostra o quanto os policiais ficam vulneráveis em suas atividades. Quanto à pesquisa documental, tornou-se possível mediante autorização da Junta Médica da PM da Paraíba, que disponibilizou os registros das licenças para tratamento de saúde durante o período de 2003 a 2005.

\section{Garantia de Segurança Pública: contextualização e finalidades}

Em termos de resgate histórico, sabe-se que a Polícia Militar, enquanto construção institucional e organizacional, confunde-se com a história do Brasil. Isto porque, desde o período Imperial, durante o governo de D. Pedro I, os presidentes das províncias não dispunham de meios apropriados para a manutenção da ordem pública, e a sua criação permitiu tal realização. Por sua vez, na Paraíba, a Polícia Militar é o mais antigo órgão público em funcionamento até hoje (Lima, 2005; Tavares, 1982).

A lógica norteadora do sistema de segurança tinha um caráter mais de proteção interna e de defesa nacional do que de atendimento aos fins de segurança pública. Tal lógica delineia uma imagem que prima pela corporação militar, ao invés de priorizar a PM enquanto organização. A efetividade de um policiamento urbano e ostensivo é rara na história da PM, mesmo considerando as peculiaridades de cada estado brasileiro (Muniz, 2001).

No Brasil, as polícias de âmbito estadual (civil e militar) têm inspiração na Europa Ocidental dos séculos XVIII e XIX, em que se concebia a segurança pública como um serviço garantido pelo Estado, para resguardar os direitos e o assentamento da autoridade. Por outro lado, existe outra concepção, que vê a polícia como uma estrutura mantenedora do status quo, dos interesses das classes abastadas (Tavares Santos, 1997; Souza e col., 2003).

Conforme Silva Filho (2003), o Brasil é o único país que concebe as atividades de polícia, tanto de prevenção quanto de investigação, como funções disjuntivas, a ponto de necessitar de duas organizações distintas em estruturas, normas administrativas e operacionais, regime disciplinar e salários. Tal distinção criou certo desgaste, enquanto modelo de controle da criminalidade, haja vista a ineficácia de seus resultados, o alto custo de manutenção e a grande complexidade de seu gerenciamento.

Segundo Sette Câmara (2002), desde a década de 1960 a PM detém a exclusividade do policiamento ostensivo fardado para realizar diversas funções como força pública. Entre essas funções, destacam-se: assegurar as instituições; garantir a ordem nos estados; atuar de maneira repressiva e/ou preventiva; atender as convocações para prevenir ou reprimir graves perturbações, tanto internas quanto ao nível do governo federal, em caso de guerra externa.

$\mathrm{O}$ acúmulo de funções atribuídas à PM, atrelado ao modelo policial pautado em atividades distintas, prevenção e investigação, fomenta questões sobre a aplicabilidade da organização do trabalho policial frente à realidade social vigente. Essas questões adquirem importância, sobretudo, quando dizem respeito às implicações desses fatores na saúde mental do policial militar.

\section{Dinâmica Social e a Organização do Trabalho da Polícia Militar (PM)}

O modelo de organização da PM continua idêntico ao do exército, com seus batalhões, companhias e pelotões, entre outros aspectos. Essa estrutura é adequada para o combate de guerra. Até a década de 1960, a PM tinha como especificidade a manutenção da ordem pública e a integridade territorial do Estado. Por volta de 1968, incorporou a exclusividade do policiamento ostensivo fardado, com o objetivo de promover a proteção coletiva. Mesmo tendo adicionado essa nova atribuição, a PM ainda mantém praticamente inalterado o modelo organizacional vigente (Sette Câmara, 2002).

Esse modelo atua em uma sociedade brasileira com características que se diferenciam daquela de algumas décadas atrás. Entre os fatores que contribuíram para essa diferenciação, está o crescimento da população urbana, com uma infraestrutura precária em termos de serviços e de políticas públicas. 0 modus operandi atual de intervenção da polícia militar foi estruturado em 1942, para atender a uma realidade brasileira distinta da que se vive hoje e, por isso, não consegue inibir o seu caráter dinâmico, crescente e de propagação da violência. 
Conforme Silva Filho (2003), a partir da década de 1970 houve a introdução gradativa de um modelo pautado na diminuição do tempo de resposta, tanto para atender às vítimas, quanto para aplicar as devidas medidas ao agressor, encaminhá-lo ou comunicar o fato a uma delegacia da cidade (para a prática de um policiamento investigativo). Essa lógica fomentou a disseminação de radiopatrulhas e o ingresso de novas tecnologias (conhecimentos e equipamentos). Entretanto, ocasionou dois problemas básicos: a centralização excessiva das ações policiais e a passividade do sistema reativo, que favoreceram o crescimento da violência.

A violência no Brasil gera um prejuízo significativo aos cofres públicos. Não existe um consenso quanto a esses custos, que atingem cifras expressivas. De acordo com Silva Filho (2003), as despesas se aproximam a R\$ 300 milhões por dia, o equivalente ao orçamento anual do Fundo Nacional de Segurança Pública.

Segundo Teixeira (2005), os setores público e privado desembolsaram juntos, no ano de 2004, aproximadamente R\$ 37 bilhões. A violência faz o Brasil perder cerca de $6 \%$ a $7 \%$ do Produto Interno Bruto (PIB). A Organização Mundial de Saúde (OMS) divulgou, em seu relatório de 2006, que a nação brasileira chega a gastar anualmente, com a violência interpessoal, 10,5\% do PIB.

Esses números apontam para um conjunto de aspectos que necessitam de reflexão, destacando-se, entre eles, os que se referem ao planejamento e à intervenção. No que tange ao presente estudo, fica claro que a organização do trabalho da Polícia Militar não consegue atender à demanda de uma população aflita, que vê a violência exceder os limites da tolerância e uma polícia que não consegue atender as consequências nefastas dessa situação.

Segundo Caravantes (2003), o modelo de organização do trabalho da Polícia Militar, pautado numa estrutura burocrática, sofre constantemente grandes críticas. Dentre essas críticas, a mais comum diz respeito à ênfase dada aos aspectos formais da organização. Esse tipo de estrutura gera uma visão parcial e faz desconsiderar drasticamente os seus trabalhadores. Além de ser uma organização burocrática, a Polícia Militar é uma instituição balizada em dois pilares fundamentais: a disciplina e a hierarquia. Isso faz dela uma organização complexa, com feixes de interesses que caracterizam a sua capacidade de resistência à mudança.

Segundo Muniz (2001), a ênfase na forma, no cargo e na função prioriza a hierarquização. A instituição policial precisa refletir sobre essas questões, uma vez que, durante o exercício de sua atividade-fim, os PMs estão expostos a situações que requerem rapidez na resolução e não podem simplesmente ser abordadas através de técnicas tradicionais de adestramento militar.

\section{A Organização do Trabalho da PM e a Subjetividade: "por trás desta farda existe um ser humano"}

A decisão dos PMs de saírem às ruas tornou-se oportuna porque, além do caráter de articulação da categoria e dos aspectos denunciatório e reivindicatório, havia uma demanda dos trabalhadores e de suas associações no sentido de mostrar à sociedade as suas reais condições de trabalho. 0 relato de um dos policiais, dizendo que "Por trás desta farda existe um ser humano [...]", serve para mostrar uma das facetas da dinâmica subjetiva do profissional de segurança pública. À primeira vista, a frase pode soar como palavra de ordem para mobilizar os PMs participantes da manifestação e sensibilizar os transeuntes e donos de estabelecimentos do comércio de João Pessoa-PB. Aos ouvidos dos especialistas do mundo do trabalho, essa fala produz uma relação de sentido que remonta à subjetividade desses profissionais.

Frequentemente, a atividade da polícia militar é considerada como "desumana" por parte dos próprios profissionais. Eles chegam a admitir que, para exercêla, é preciso ser um "robocop", ou seja, uma máquina cujas capacidades humanas devem ser subtraídas ${ }^{3}$. Nesse sentido, é importante considerar algumas determinações que podem estar na origem dessa concepção, sendo que a principal delas é a própria formação dos policiais.

Em um estudo realizado com policiais militares de Porto Alegre-RS, Amador (1999) verificou que existe o pressuposto de que o policial tem de exercer suas atividades com "total” controle. Esse controle deve ser

3 Essas capacidades incluem pensar, sentir, experimentar inseguranças e medos, bem como outros elementos que compõem a subjetividade. 
empreendido de forma constante e permanente, através de ações exatas, devido às características peculiares da própria organização do trabalho.

Dessa maneira, mesmo com as transformações ocorridas no mundo do trabalho, com a emergência de novas políticas de gestão da força de trabalho, além do estabelecimento de uma série de técnicas, ferramentas e ideologias para gerir conflitos, ainda permanece a ideia da falta de controle do próprio trabalhador sobre o seu savoir-faire. Quando se fala de organização burocrática da polícia, observa-se com mais clareza essa ideia, porque existe uma ênfase na hierarquia, com total separação entre quem pensa e quem executa, ou melhor, as relações passam a ter outras concepções.

Essa dicotomia entre o pensar e o executar pode abrir espaço para a ação truculenta (por vezes arbitrária) das relações entre os níveis hierárquicos da polícia e, até mesmo, entre as próprias polícias. Isso contribui para o aumento do medo generalizado da população, a qual, por conseguinte, desenvolve uma imagem negativa dos policiais. Souza e Patrocínio (1999) mostraram, em seus estudos, que o policial é visto pela sociedade como a segunda categoria profissional merecedora dos piores adjetivos, perdendo apenas para os lixeiros.

Sejam eles civis ou militares, os policiais em atividade-fim caminham, na maioria das vezes, no limiar entre a vida e a morte. Uma vez que sempre agem sistematicamente em áreas conflituosas, estão constantemente expostos ao risco de morte. Esse risco de morte constante acontece tanto na área rural, devido ao alto índice de conflitos sociais/agrários, quanto nas cidades, por causa da criminalidade e da violência (Tavares Santos, 1997).

Segundo Sette Câmara (2002), quando o policial é acionado para atender uma ocorrência, é como se entrasse em um terreno movediço. Essa percepção acontece porque se trata de uma situação de conflitos, que envolve pessoas. Quando o PM chega ao local, logo se depara com um cenário complexo: Quem é o bandido, o infrator, a vítima? Quem está certo ou errado? 0 motivo que suscitou sua presença trata-se de um ato ilícito? E se for preciso utilizar a força - ou a arma -, qual deve ser o limite? Qual o melhor procedimento a adotar? Tudo isso se decide rapidamente. Um erro de avaliação pode lhe ser fatal ou induzi-lo a comportamentos equivocados.

\section{Os Constrangimentos no Trabalho e as Crises Mentais na PMPB}

A polícia é uma instituição pública de prestação de serviços, com o propósito de fazer valer o direito à segurança. Assim sendo, pode-se dizer que a atividade do policial sofre pressões decorrentes tanto da organização do trabalho quanto dos fenômenos sociais. Outro elemento que se incorpora a essa dinâmica, formando uma tríade, é a precarização do trabalho.

A precarização é resultante de um processo instituído por fatores sociais, políticos e econômicos, que estão presentes nas condições impróprias de trabalho. Nesse sentido, é vivenciada de formas distintas, segundo as populações vulneráveis que compõem a sociedade como todo (Vieira, 200o; Vieira e Araújo, 2003).

No caso dos policiais militares, a precarização das condições de trabalho pode ser proveniente dos equipamentos e instrumentos inadequados, da restrição de recursos orçamentários para a manutenção desses equipamentos, dos salários desproporcionais e da falta de capacitação profissional. Esses fatores acabam configurando um quadro desfavorável tanto para a eficiência do trabalho policial, quanto para a própria saúde dos PMs.

O sentimento de insatisfação no trabalho e o comprometimento da saúde dos policiais podem ser expressos nos depoimentos proferidos pelos próprios profissionais de segurança pública. Um exemplo disso pode ser encontrado nos seguintes relatos: "Faz três anos que as nossas fardas não são trocadas [...] Nossas viaturas são e estão em péssimas condições [...] Nossas armas estão bem mais atrasadas que as dos bandidos que vem de fora [...]".

Esses relatos demonstram uma precarização do trabalho, no que diz respeito às armas obsoletas, às viaturas insuficientes e em más condições de uso, à falta de reconhecimento tanto por parte da instituição como pela sociedade, além dos baixos salários. Esses fatores externos aumentam os constragimentos na tarefa (contraintes), o que, por sua vez, exige do PM um esforço maior para realizá-la (astreinte).

Ao discutir a organização do trabalho, a carga mental e o sofrimento psíquico, Wisner (1994) menciona que a situação de trabalho é composta por três componentes: físico, cognitivo e psíquico. Cada um 
desses componentes pode ser caracterizado por um conjunto de esforços empreendidos no cumprimento das exigências das tarefas, podendo determinar uma sobrecarga de trabalho.

A partir do momento em que cada um desses componentes é inflado por fatores que compõem a situação de trabalho, instala-se uma sobrecarga ou um sofrimento. Pois o trabalhador terá a necessidade de se desdobrar para realizar sua tarefa, o que acarretará algum ônus para ele.

Enquanto os dois primeiros componentes são bastante evidentes, a carga psíquica apresenta dificuldades quanto à sua caracterização. Ela pode ser definida como a dinâmica dos elementos conscientes e inconscientes, nas relações entre as pessoas e a organização do trabalho. No entender de Wisner (1994), o componente psíquico refere-se ao significado que o conteúdo e a organização do trabalho representam para cada trabalhador.

Dejours e colaboradores (1993) apresentam outra explicação para o que se passa na interface homem-atividade, quando descrevem que o trabalhador gerencia um conjunto de excitações, internas e externas, que emergem da situação de trabalho. As primeiras se referem às excitações do sujeito, como instinto, pulsão, inveja e desejo, entre outras. As externas se referem às informações visuais, auditivas, táteis e outras, oriundas do meio em que o sujeito se encontra. Ao se acumularem, essas excitações tornam-se o epicentro de uma tensão psíquica, popularmente conhecida como tensão nervosa, que pode ser liberada pelas vias psíquica, motora e visceral.

A organização de trabalho adequada é aquela que faculta ao trabalhador as condições necessárias para o escoamento dessas tensões. De acordo com Dejours e Abdoucheli (1994), a organização de trabalho deve ser entendida em sentido amplo, abrangendo tanto a divisão de tarefas, quanto a maneira como os homens se estruturam na sociedade. 0 primeiro tipo de organização se dá entre os operadores, refletindo a repartição das tarefas, a cadência e o modo operatório que é prescrito para realizá-las. A organização que se dá entre os homens refere-se ao âmbito da responsabili- dade, da hierarquia, da chefia e do controle. Segundo os autores, enquanto a organização do trabalho reverbera na dimensão psíquica do sujeito, as condições de trabalho têm na estrutura física do trabalhador a sua visibilidade. Desse modo, a forma como a organização se estrutura tem implicações tanto no bem-estar do trabalhador e no sucesso dos bens e serviços, quanto na produção de sofrimento patogênico e de doenças mentais.

A relação entre os aspectos objetivos e subjetivos no trabalho do militar estadual em atividade-fim pontuase por uma miríade de constrangimentos (contraintes), com muitos PMs sentindo os efeitos nefastos dessas pressões. É o que as lideranças da Polícia Militar da Paraíba (PMPB) afirmam quando expõem suas preocupações sobre o alto índice de dependência química (alcoolismo), o constante estresse, o elevado número de depressão e o suicídio entre os PMs.

No contexto da PM, as pressões da organização do trabalho e a sociedade aflita são fatores que podem influenciar no aumento da fadiga e nas crises mentais. O percentual de aposentadorias por invalidez devido a transtornos psiquiátricos, que foram homologadas pela junta médica da PMPB, em 1998, equivale a $25,5 \%$. Outro dado importante é que cerca de $75,8 \%$ desses reformados situam-se na faixa de 20 a 29 anos $^{4}$, ou seja, estão entre os profissionais que se aposentaram ainda jovens, praticamente em início de carreira. Considerando o escalonamento hierárquico da PM, verifica-se que 73,2\% dos mais afetados são os soldados e cabos, já que eles apresentam maiores chances de envolvimento com operações de risco, em função das demandas da sociedade, cada vez mais cadenciada pela violência.

No período de 1995 a 1998, a junta médica da PM homologou 74 reformas por invalidez, das quais $41,9 \%$ foram por motivo de ordem mental 5 . Os dados também apontam certos fatores que contribuem para o sofrimento psíquico desses profissionais, a saber: baixos salários (92\%), carga excessiva de trabalho (69\%) e condições de trabalho desfavoráveis (61\%).

Para suprir a limitação salarial, os PMs realizam outros trabalhos, os chamados bicos, com o propósito de complementar a renda mensal. Na maioria das

4 Para uma apreciação desses dados, ver Paixão (1998) monografia de especialização em Segurança Pública pela Academia de Polícia Militar do Cabo Branco, João Pessoa/PB.

5 Para uma apreciação desses dados, ver Assunção (1998) monografia de especialização em Segurança Pública pela Academia de Polícia Militar do Cabo Branco, João Pessoa/PB. 
vezes, esses trabalhos são em serviços de segurança particular de eventos privados ou de estabelecimentos comerciais. Ao desempenharem outras atividades, os PMs criam um acúmulo de horas, que são incorporadas à sua rotina de serviço estadual, comprometendo os seus momentos de repouso, lazer e convívio familiar.

Silva (2007) faz referência à Tabela I, que apresenta o número de licenças médicas concedidas no período compreendido entre 2003 e 2005. Mesmo com um efetivo de sete mil policiais nos dois primeiros anos, e com um aumento de 500 integrantes, devido à realização de concurso público no último ano, manteve-se uma média de 489 licenças no período estudado. Isto é, aproximadamente 7,6\% dos PMs se afastaram para tratamento de saúde em 2003, enquanto, no ano seguinte, esse percentual caiu para $6,9 \%$, mantendo-se nesse patamar em $2005^{6}$.

Certamente este quadro de licenças para tratamento de saúde seria outro se as negociações no local de trabalho também fossem computadas. Em determinadas ocasiões, dependendo do seu bom comportamento, muitos policiais nem precisam ir à Junta Médica. O que de fato acontece é que há uma solução interna entre os pares, com a devida autorização dos superiores, que torna possível a ausência desses profissionais, por certo tempo. Caso não houvesse o emprego desse recurso, ou se ele fosse considerado estatisticamente, o número das licenças seria indubitavelmente maior.

Um aspecto importante dessa situação é que os policiais declaram que se "licenciam para não licenciarem". Ou seja, esses profissionais empregam uma estratégia de faltar durante uns dias para não se ausentarem por longos períodos no exercício de suas atividades. Como não há uma ação articulada de saúde no trabalho de $\mathrm{PM}$, os próprios policiais buscam uma forma de reagir ao que compromete a sua disposição física e mental.

Segundo Brito e colaboradores (2003), os trabalhadores desenvolvem capacidades de perceber, interpretar e reagir, bem ou mal, consciente ou inconsciente, ao que afeta a sua saúde no trabalho. Neves (1999) também encontrou tal procedimento estratégico em outra categoria de servidores públicos, a dos professores. A pesquisa mostrou que os professores faltavam nos dias menos complicados para o funcionamento da escola, ou seja, "faltavam para não faltarem".

\section{À Guisa de Conclusão}

Apesar de se revestir de um caráter introdutório, o presente estudo permite delinear alguns aspectos envolvidos na relação causal entre a atividade policial e a saúde mental. Nesse sentido, a própria delimitação da categoria profissional pode contribuir para suscitar a realização de outras pesquisas sobre o tema, de modo a respaldar intervenções em prol da saúde no trabalho policial.

As reflexões sobre a saúde no trabalho policial ainda são bastante limitadas. Isso não é por acaso, principalmente no Brasil, em que os espaços silenciosos instituídos durante o período da ditadura militar continuam a ecoar até hoje. Assim, o ônus sofrido nas últimas décadas caracterizou um espaço, pós-regime militar, não muito propício para se tratar de temas versados sobre a polícia, pois quem o fizesse não era bem visto pela sociedade.

Além de ser uma organização burocrática, com raízes no século XIX, a Polícia Militar traz, na sua base, os princípios da hierarquia e da disciplina. Esses pilares de sustentação fazem da Polícia uma organização complexa, com feixes de interesses que dificultam as possibilidades de mudanças estruturais que deem conta da realidade de violência cotidiana, tanto nos grandes e pequenos centros, quanto nas áreas rurais. Esse distanciamento cristalizou uma lógica de preservação de interesses restritos apenas à corporação militar, priorizando o status que a graduação hierárquica proporciona e a função desempenhada na polícia, em detrimento da organização como um todo.

A organização do trabalho policial e a dinâmica da violência, cadenciando novos ritmos de convivência na sociedade, são fatores que não só comprometem a economia do país, mas também afetam a saúde dos cidadãos. Esses aspectos colocam o policial militar no centro de uma conjugação de forças, exigindo dele um verdadeiro e constante combate, que também é travado com o componente de precarização do trabalho.

Ou seja, no contexto do militares estaduais, é preciso considerar tanto os aspectos de organização do trabalho quanto as situações de risco a que esses profissionais estão expostos, principalmente pelo aumento significativo da violência e pela precarização

6 Todavia, é importante lembrar que, em 2005, houve um aumento no efetivo. 
do trabalho. É a sinergia desses componentes que pode ocasionar implicações na saúde mental desses profissionais. É a maneira como essas forças interagem e o embate que é vivido cotidianamente pelo policial em sua atividade-fim, que terminam por gerar o sofrimento psíquico, com possíveis desdobramentos em alcoolismo, depressão e até mesmo em suicídio.

Com base nessas considerações, quaisquer intervenções que se pretenda realizar no âmbito da polícia militar, com o intuito de articular eficiência e melhoria nos serviços de segurança pública, devem abranger, primeiramente, propostas efetivas na organização e modernização do processo estrutural de trabalho. Além disso, devem visar o melhoramento das condições dos equipamentos e instrumentos destinados à realização do trabalho policial.

Não se pode esquecer de que implementações desse porte exigem esforços que englobam as variadas camadas do Poder e a realização de políticas públicas voltadas para a diminuição da violência social e da criminalidade, que vitimam não só os cidadãos, mas também os próprios policiais. São esses esforços que, aliados a uma maior união das entidades defensoras de Direitos Humanos, poderão lograr a efetivação de ações exequíveis, em prol da saúde mental no trabalho policial.

Tabela I - Registros das licenças para tratamento de saúde entre 2003 e 2005

\begin{tabular}{l|c|c|c} 
Meses & $\begin{array}{c}\text { Lic. Trat. de } \\
\text { Saúde-2003 }\end{array}$ & $\begin{array}{c}\text { Lic. Trat. de } \\
\text { Saúde-2004 }\end{array}$ & $\begin{array}{c}\text { Lic. Trat. de } \\
\text { Saúde - 2005 }\end{array}$ \\
\hline Jan & 35 & 43 & 39 \\
\hline Fev & 56 & 51 & 35 \\
\hline Mar & 39 & 34 & 51 \\
\hline Abr & 43 & 36 & 47 \\
\hline Mai & 39 & 40 & 40 \\
\hline Jun & 44 & 46 & 40 \\
\hline Jul & 46 & 41 & 37 \\
\hline Ago & 39 & 43 & 53 \\
\hline Set & 39 & 41 & 52 \\
\hline Out & 35 & 38 & 34 \\
\hline Nov & 44 & 40 & 37 \\
\hline Dez & 35 & 29 & 26 \\
\hline Total & 494 & 482 & 491 \\
\hline
\end{tabular}

Fonte: Junta Médica da PM-PB, 2006.

\section{Referências}

AMADOR, F. S. Trabalho e saúde: considerações a respeito da categoria dos policiais militares. Unidade, Porto Alegre, v. XVII, n. 40, p. 43-55, 1999.

BRITO, J.; NEVES, M. Y.; ATHAYDE, M. Caderno de método e procedimentos: programa de formação em saúde, gênero e trabalho nas escolas. João Pessoa: Ed. Universitária UFPB, 2003.

CARAVANTES, G. R. Teoria geral da administração: pensando e fazendo. Porto Alegre: AGE, 2003.

DEJOURS, C. A loucura do trabalho: estudos de psicopatologia do trabalho. São Paulo: Cortez-Oborê, 1987.

DEJOURS, C.; ABDOUCHELI, E. Itinerário teórico de psicopatologia do trabalho. In: DEJOURS, C.; ABDOUCHELI, E.; JAYET, C. Psicodinâmica do trabalho: contribuições da escola dejouriana à análise da relação prazer, sofrimento e trabalho. São Paulo: Atlas, 1994. p. 119-145.

DEJOURS, C.; DESSORS, D.; DESRIAUX, F. Por um trabalho, fator de equilíbrio. Revista de Administração de Empresas, São Paulo, v. 33, n. 3, p. 98-104, maio/jun. 1993.

FERNANDES, C. Criminalidade é crescente. Correio da Paraỉba, João Pessoa, 16 set. 2007. Cidades, p. B3. GUÉRIN, F. et al. Compreender o trabalho para transformá-lo: a prática da ergonomia. São Paulo: Edgard Blücher, 2004.

GOUVEIA, J. F. Polícia Militar e violência: reflexão. Jus Navigandi, Teresina, ano 3, n. 34, ago. 1999. Disponível em: <http://jus2.uol.com.br/doutrina/ texto.asp?id=1588>. Acesso em: 27 out. 2005 .

LIMA, B. J. História da Polícia Militar da Paraiba. Disponível em: <www.pm.pb.gov.br/newsite/arquivos/ historia_da_pmpb.pdf $>$. Acesso em: 7 maio 2005. MUNIZ, J. O. A crise de identidade das polícias militares brasileiras: dilemas e paradoxos da formação educacional. Security and Defense Studies Review, Winter, v. 1, p. 177-198, 2001.

NEVES, M. Y. Trabalho docente e saúde mental: a dor e a delícia de ser (tornar-se) professora. 1999. Tese - Universidade Federal do Rio de Janeiro, Rio de Janeiro, 1999. 
PERES, M. F. T. Violência: um problema de saúde pública. In: LIMA, S. R.; PAULA, L. Segurança pública e violência: o Estado está cumprindo o seu papel? São Paulo: Contexto, 2006. p. 101-112.

SENASP - SECRETARIA NACIONAL DE SEGURANÇA PÚBLICA DO MINISTÉRIO DA JUSTIÇA. Distribuição das Ocorrências Registradas pela Polícia Civil entre 2001e 2003. Disponível em: <http://www.mj.gov.br/ senasp/pesquisas_aplicadas/mapa/rel/sit_total.htm>. Acesso em: 8 set. 2006.

SETTE CÂMARA, P. Reflexões sobre segurança pública. Belém: Universidade da Amazônia, 2002.

SILVA, M. B. Trabalho de Polícia Militar e saúde mental: um estudo de caso sobre sofrimento psíquico e prazer na atividade de radiopatrulha. 2007. Dissertação (Mestrado em Engenharia de Produção) - Universidade Federal da Paraíba, João Pessoa, 2007.

SILVA FILHO, J. V. S. Segurança pública: a violência no Brasil requer ações concretas. São Paulo: Instituto Fernand Braudel, 2003. Disponível em: <http://www.braudel.org.br/paper34a.htm>. Acesso em: 20 set. 2005 .

SOUZA, E. M. C. D.; PATROCÍNIO, M. C. C. Fatores psicossociais na gênese de atos agressivos de policiais militares. In: SAMPAIO, J. R. et al. Qualidade de vida, saúde mental e psicologia social: estudos contemporâneos II. São Paulo: Casa do Psicólogo, 1999. p. 181-216.
SOUZA, E. R.; MINAYO, M. C. S.; ASSIS, S. G.

Construção histórica de uma categoria social. In: MINAYO, M. C. S.; SOUZA, E. R. Missão investigar: entre o ideal e a realidade de ser policial. Rio de Janeiro: Garamond, 2003. p. 51-78.

TAVARES, E. C. Século e meio de bravura e heroísmo: documentário histórico sobre a origem e evolução da Policia Militar da Paraíba. João Pessoa: [s.n.], 1982.

TAVARES SANTOS, J. V. A arma e a flor: formação da organização policial, consenso e violência. Tempo Social, São Paulo, v. 9, n. 1, p. 155-167, maio, 1997.

TEIXEIRA, I. B. O alarmante custo da violência. Dinheiro na Web, n. 139, 26 abr. 2005. Disponível em: <http://www.terra.com.br/dinheironaweb/139/ entrevista/ent139_o1.htm>. Acesso em: 10 dez. 2005.

VIEIRA, S. V. Situação de trabalho e saúde mental em uma clínica obstétrica. 200o. Tese - Universidade Federal do Rio de Janeiro, Rio de Janeiro, 2000.

VIEIRA, S. B.; ARAÚJO, A. J. Gênero, precarização e saúde no trabalho hospitalar. In: CARVALHO, M. E.; PEREIRA, M. Z. Gênero e educação: múltiplas faces. João Pessoa: Ed. Universitária UFPB, 2003. p. 149191.

WISNER, A. A inteligência no trabalho: textos selecionados de ergonomia. São Paulo: Fundacentro, 1994. 